\title{
MERCHANDISING SOCIAL: A DINÂMICA DO TERMO E SUA APROPRIAÇÃO PELA TELEDRAMATURGIA
}

\author{
MERCHANDISING SOCIAL: THE DYNAMICS OF YOUR TERM AND \\ APPROPRIATION BY TELEDRAMATURGY \\ MERCHANDISING SOCIAL: LA DINÁMICA DE SU PLAZO Y \\ PROPIEDAD POR TELEDRAMATURGIA
}

Plábio Marcos Martins Desidério

Doutor, Universidade Federal do Tocantins

plabiom@gmail.com

\section{Resumo}

Este artigo se propõe a mapear o termo merchandising e sua apropriação pela teledramaturgia brasileira. Essa apropriação é utilizada por alguns dramaturgos de televisão, como Manoel e Glória Perez, a partir da principal produtora de telenovela, a Rede Globo. O termo passou a ser conhecido como merchandising social para referi-se à inserção de ações sócio-educativas visando influenciar comportamentos desviantes e que prejudicam o convívio social. Essa análise procurou compreender como o termo merchandising social se desdobrou nos últimos anos na televisão, a partir das contribuições de autores que analisam a presença e importância do merchandising na atualidade e como esse termo transborda para a televisão, em especial para a telenovela.

Palavras-chave: Merchandising Social. Apropriação. Teledramaturgia.

\begin{abstract}
This article intends to map the term merchandising and its appropriation by brazilian television drama. This appropriation is used by some television playwrights, such as Manuel and Gloria Perez, from the main producer of telenovela, Rede Globo. The term came to be known as social merchandising refers to the inclusion of socio-educational activities aimed at influencing and deviant behaviors that impair social life. This analysis sought to understand how the term social merchandising unfolded in recent years in television, from the contributions of authors analyze the presence and importance of merchandising at present and as that term overflows for television, especially for the telenovela.
\end{abstract}

Keywords: Social Merchandising. Appropriation. Teledramaturgy. 


\section{Resúmen}

Este artículo tiene la intención de asignar el merchandising término y su apropiación por parte de la teledramaturgia brasileña. Esta asignación es utilizada por algunos autores dramáticos de televisión, como Manuel y Gloria Pérez, de la casa del productor de telenovelas, Rede Globo. El término ha llegado a ser conocido como el merchandising social, se refirió a la inclusión de las actividades socio-educativas dirigidas a influir en la conducta desviada y dificultan la interacción social. Este análisis busca entender cómo el merchandising social a largo plazo se desarrolló en la televisión en los últimos años, sobre la base de las contribuciones de los autores analizar la presencia y la importancia de la comercialización de hoy, y como dicho término se desborda para la televisión, especialmente para la telenovela.

Palabras clave: Merchandising Social. Apropriación. Teledramaturgia

\section{INTRODUÇÃO}

O termo merchandising é utilizado por áreas da comunicação (com ênfase na publicidade) e administração de empresas para referirem-se à promoção de produtos e serviços através de campanhas publicitárias. O termo está em consonância com o marketing, pois ambos têm como objetivo principal divulgar produtos, serviços e até mesmo ideias, a partir de um processo de gestão que consiga coordenar as práticas do marketing e também do merchandising. O marketing, na atualidade, se desdobra para várias atuações, seja no fortalecimento de produtos e/ou serviços de determinada organização, na construção e consolidação de uma marca, ou, mesmo, como propõe este trabalho, para análise de alguns desdobramentos do marketing social. O marketing social é constantemente utilizado para se referir à divulgação de ideias e conteúdos sociais em forma de campanhas publicitárias realizadas por empresas e também por outras organizações.

A palavra merchandising, na sua origem inglesa, possui vários significados. Escrita como merchandise, significa mercadoria. Merchandiser (r), por sua vez significaria negociante (BLESSA, 2001, p.131). A tradução literal de merchandising corresponderia à mercandização, palavra que não produz muito sentido na língua portuguesa. Portanto, a tradução mais apropriada de merchandising deriva da palavra merchandise, que pode ser entendida como operação com mercadorias. O merchandising torna-se, assim, uma prática dentro do mercado de varejo, procurando dar visibilidade às mercadorias, adotando estratégias publicitárias. $\mathrm{O}$ merchandising é 
uma prática inserida nas estratégias do marketing, presente no estudo da disciplina de administração de empresas, bem como no espaço corporativo.

Autores, como Philip Kotler e Michael J. Baker analisaram estratégias de como alcançar um marketing eficiente. Eles procuraram perceber a importância do marketing para a própria eficiência e dinâmica das organizações. Porém, o marketing não se restringe apenas às estratégias de propaganda e publicidade de produtos, mas também de ideias e valores das organizações e de promoção do social e é nesse momento que entra o marketing social. O marketing torna-se um elemento crucial para as organizações, principalmente nas últimas décadas do século $\mathrm{XX}$, desempenhando um papel fundamental para as estratégias de várias empresas.

A amplitude da disciplina de marketing e sua relevância nas estruturas empresariais denotam desde aspectos de comportamento do consumidor, formação de preços, poder de compra, gestão de vendas, gestão de produtos, processo de comunicação, análise da concorrência, marketing social, ética empresarial e canais de distribuição e até aspectos sociológicos, psicológicos e culturais em sua estrutura teórica. Um ponto relevante no direcionamento do marketing nas organizações atuais é sua nova definição na American Marketing Association, que o coloca como "uma função organizacional e uma série de processos para a criação, comunicação e entrega de valor para clientes, e para a gerência de relacionamentos com eles, de forma que beneficie a organização e seus stakeholders". (AMA, 2004).

Por esta nova conceituação é importante conciliar os fluxos existentes nos 4 P’s - Produto, Praça, Preço e Propaganda - nas estratégias empresariais, as quais serão exponencialmente úteis ao entendimento e sinergia da empresa com o mercado, para conciliar suas competências internas com os requisitos dos clientes, tanto para empresas com fins lucrativos como às sem fins lucrativos. Kotler (1998) sugere no processo de mapeamento e prospecção de novos produtos a participação profunda das ferramentas de marketing para o aumento da probabilidade de sucesso nos projetos. Sugerindo também uma sequência de oito estágios que permite sua efetividade, partindo da geração de ideias, triagem, desenvolvimento e teste de conceito, estratégia de marketing, análise comercial, desenvolvimento de produto, teste de mercado e comercialização.

Outro comportamento latente da sociedade é a preocupação com a preservação da qualidade do meio ambiente para um convívio saudável. Por esta perspectiva, surge o marketing societal, como nova premissa estratégica nas 
organizações que, por definição de Kotler (1998), ratifica que a tarefa da organização é determinar as necessidades, desejos e interesses dos mercados-alvo e atende às satisfações desejadas mais eficaz e eficientemente do que os concorrentes, de maneira a preservar ou ampliar o bem estar dos consumidores e da sociedade.

A representatividade das estratégias de marketing nos planejamentos de sobrevivência das organizações é intrínseca nas atitudes e posicionamentos empresariais, principalmente com a maior demanda por proximidade com o mercado e com as interpretações cada vez mais complexas dos valores simbólicos traduzidos em produtos no mercado. A formatação do design dos produtos, a concepção das embalagens e o processo comunicativo com o público-alvo defrontam-se atualmente com diversas terminologias consolidadas no mercado de consumo em massa e são regidas pela precificação ${ }^{1}$, num estilo bastante adotado na rede americana de supermercados Wal-Mart. O mercado neste século tendencia para uma personificação no relacionamento, não abrangendo exclusivamente um atendimento uníssono, mas ampliando a ótica de percepção do relacionamento com o cliente, numa geração cíclica de condicionamentos e durabilidade das relações enquanto atratividade para ambas as partes.

Várias organizações começaram, especialmente nos E.U.A, nos últimos tempos, a adotar estratégias de marketing social, com vistas a inserir em suas campanhas publicitárias e nas metas da organização a divulgação de ações éticas e educativas, promovidas por elas próprias. Essas organizações são empresas que se destacaram, principalmente a partir da década de 70, por suas iniciativas em construir uma imagem de empresas de consciência social. Empresas como American Express, Avon, Procter \& Gamble e o Cooperative Bank são exemplos nos E.U.A de organizações que conseguiram avançar no marketing em relação às causas sociais ( PRINGLE \& THOMPSON, 2000, p. XXI). Desde o início do século, algumas empresas, como a Austin Motor Company, procuravam utilizar práticas que viriam a ser consideradas como marketing social. Essas ações com caráter promocional visam promover, seja pelas empresas públicas ou, pelas privadas, um marketing - neste caso o social - tendo por objetivo construir uma "imagem" de instituição socialmente responsável.

\footnotetext{
${ }^{1}$ Precificação é a atividade de marketing que se preocupa em fixar o preço dos produtos fazendo parte do espaço mercadológico.
} 


\section{A PRÁtiCA DO MERCHANDISING SOCIAL NA TELENOVELA BRASILEIRA}

\subsection{Merchandising social e seu didatismo na dramaturgia televisiva.}

O merchandising social tem, assim, como estrutura precursora, o marketing social, que pode ser caracterizado como uma "ferramenta" que posiciona a empresa e sua marca, associando-as a uma questão social relevante, com a intenção de obter vantagens mútuas (PRINGLE \&THOMPSON, 2000, p. 03). Um dos objetivos do marketing social para Pringle \& Thompson (2000) é melhorar a imagem corporativa da empresa e produzir uma fidelização do cliente, num ambiente competitivo em que os produtos são cada vez mais commodities $^{2}$, parecidos, copiados, mas possuindo as mesmas funções. $\mathrm{O}$ marketing para causas sociais seria um diferencial para as empresas produzirem um outro valor e agregá-lo à sua marca.

O marketing social procura dentro das estratégias definidas pela empresa atingir, ao mesmo tempo, os objetivos das organizações bem como adequá-la às necessidades dos clientes, seja por produtos e serviços, seja também por problemas cotidianos. Como o marketing social está presente num ambiente corporativo, ele é regido, também, por regras e elementos de competição e maximização de resultados, e sua definição pode ser percebida como projetos para atingirem públicos-alvo, envolvendo segmentação de mercado, pesquisa de consumidores e processos de comunicação, com o objetivo de estabelecer uma relação de troca entre empresa e público e construir um efeito esperado (KOTLER, in LEVEK, 2002, p. 21). O marketing social torna-se um instrumento para as organizações com o intuito de estabelecer uma comunicação direta com o público, como a construção de uma marca para a própria organização. Essa marca pode ser agregada aos produtos existentes, como também pode ser um novo produto que a organização configure para incorporar novas estratégias.

Os E.U.A foram o espaço, onde o marketing se estabeleceu, e cujo marketing para as causas sociais tornou-se um elemento presente em vários organizações. Pode-se ter como exemplo a empresa norte-americana Avon que ao elaborar uma campanha de conscientização sobre o câncer de mama adotou essa prática

\footnotetext{
${ }^{2} \mathrm{O}$ termo commodities está sendo utilizado para se referir às mercadorias que são produzidas em grande escala, cada vez mais padronizadas, procurando atingir um público exigente.
} 
como estratégia, agregando-a aos seus produtos como uma ferramenta para que a marca, sua imagem, e, portanto, os seus produtos tivessem confiança e um diferencial junto ao público. (PRINGLE \& THOMPSON, 2000, p. 34). O marketing para as causas sociais, como é mais conhecido nesse país, se apropria dos produtos para divulgar ideias, valores que estimulem uma responsabilidade social mútua. Nesse caso, o marketing social é uma adequação muito próxima do marketing comercial, pois os próprios produtos "carregam" a divulgação dos princípios conscientizadores. Outro elemento importante é que no tipo de marketing social norte-americano ocorre consideravelmente a filantropia que contribui para as organizações agregarem ou retroalimentar sua marca pública.

No Brasil, o marketing social tornou-se uma preocupação entre as organizações, sobretudo a partir da década de 80 . A prática em nosso país possui vários entrecruzamentos, recebendo influência da prática norte-americana, mas também da proposta realizada por organizações internacionais como a ONU para a mobilização social, que procura estabelecer soluções para problemas na sociedade civil. Imbuídas nesse processo, várias organizações como empresas, ONG's (Organizações nãogovernamentais, hoje conhecidas como terceiro setor) e entidades públicas procuraram estabelecer metas para desenvolver projetos de responsabilidade social. Um exemplo da expansão dessa prática entre as organizações pode ser percebido a partir do monitoramento do instituto ETHOS, criado em 1998, em São Paulo, que reúne empresas (através de um processo de associação) para estimular as empresas a gerirem seus negócios de forma ética e responsável socialmente. Uma empresa associada a esse instituto e que faz parte desta pesquisa é a Rede Globo.

A responsabilidade social tornou-se um espaço de discussão e estabelecimentos de metas para que várias organizações assumissem cada vez mais compromissos de respeito ao coletivo e ao meio ambiente, ao consumidor, muitas vezes possuindo características semelhantes com o marketing social. Porém, as organizações que aderem à responsabilidade social estão procurando assumir um compromisso social maior do aquele presente nas estratégias do marketing social. No Brasil muitas empresas incorporaram as características do marketing social, como foi evidenciado e também os elementos da responsabilidade social.

O merchandising social praticado por emissoras de televisão como a Rede Globo se constitui a partir do momento em que esta procura aderir à responsabilidade social, incorporando também características do marketing social. Mas, qual é o porquê 
da utilização do termo merchandising social pela Rede Globo? Merchandising social é compreendido como um conjunto de mensagens socioeducativas inseridas nas tramas das produções ficcionais. Como afirmam Lopes e Gómez:

\begin{abstract}
Merchandising social é definido como uma estratégia de comunicação que consiste na veiculação, nas tramas e enredos das produções de teledramaturgia e nos programas de entretenimento, de mensagens socioeducativas que permitem à audiência extrair ensinamentos e reflexões capazes de mudar positivamente seus conhecimentos, valores, atitudes e práticas. O que caracteriza o merchandising social é a presença de referências de medidas preventivas, protetoras, reparadoras ou punitivas; alerta para causas e consequiências associadas, ou quanto a hábitos e comportamentos inadequados etc. (LOPES, 2009, p. 153).
\end{abstract}

Porém, para compreender a presença do merchandising social nas telenovelas da Rede Globo é necessário perceber que a emissora utilizava outros tipos de merchandising, sobretudo o comercial, influenciando inclusive na construção das tramas e, com isso, na consolidação da dramaturgia televisiva.

O merchandising comercial é um elemento importante na Rede Globo, estando presente na narrativa ficcional e na dinâmica das tramas. A primeira novela que apresentou uma ação de merchandising comercial foi Beto Rockfeller, quando apareceu um antiácido sendo consumido pelo protagonista. Porém, a novela que iniciou a popularização da propaganda de produtos foi Cavalo de Aço, exibida em 1973, quando foi destacada uma marca de bebida. Segundo Muniz Sodré, essa mensagem publicitária foi realizada de forma espontânea, porém com forte apelo comercial (SODRÉ, 2001, p. 73). A partir dessa experiência, a Rede Globo percebeu que é possível inserir nas tramas propagandas de vários produtos, se utilizando das ações dos personagens e principalmente aferir vantagens econômicas desse procedimento. O merchandising comercial passa a ser um elemento importante para a construção da dramaturgia televisiva, destacadamente na Rede Globo, pois suas novelas passam a incorporá-lo nas suas tramas.

Para a Rede Globo, o merchandising comercial tornou-se uma importante fonte de dividendos. A empresa aumentou, com esta prática, o número de anunciantes. O merchandising comercial, portanto, constitui-se em uma estratégia de marketing dentro da racionalidade comercial da Rede Globo para manter a produção ficcional desta e alcançar os níveis de audiências satisfatórios, atraindo esses mesmos anunciantes 
para inserir o sinal de merchandising (quando apenas expõe o produto) ou mesmo a "ação de merchandising" (quando envolve diretamente a ação de um personagem com o produto que se quer anunciar). Todos esses dois tipos de merchandising comercial presentes na narrativa envolvem não apenas os elementos de uma publicidade direta de produtos ao público. Porém, especialmente ao incorporar uma ação pelo próprio personagem, na própria trama.

Como o merchandising comercial está presente nas tramas e, inclusive nas ações dos personagens, o que se veicula não é apenas o produto, mas também um estilo de vida, hábitos, costumes, um padrão de vida oferecendo, portanto, a participação do sistema capitalista. Como Pallottini observa, ao oferecer os produtos do capitalismo, como automóveis, serviços bancários, não se veicula somente isso, está sendo veiculado também o merchandising de ideias e também a perspectiva do autor da novela:

\begin{abstract}
O que queremos dizer é o seguinte (e aqui voltamos ao ponto já discutido anteriormente): suponhamos que uma telenovela de muito sucesso, de grande audiência, veicule os hábitos, os costumes, o modo de vida, por exemplo, de determinada fatia da população carioca - Rio de Janeiro, zona sul. Não se pode culpar o autor pode fazê-lo, pois esse é o seu mundo. Por outro lado, é um mundo simpático, bonito, charmoso - com meninas atraentes, rapazes fortes e bronzeados, praias, iates, festas, jantares, dinheiro, enfim. Misturados a esse ambiente vê os costumes próprios do grupo: leveza sexual, tolerância, promiscuidade, adultério, bebida, drogas [...] (PALLOTTINI, 1998, p. 129-130).
\end{abstract}

O merchandising de ideias, segundo Pallottini (1998, p. 70), tornou-se um elemento importante na constituição das tramas, pois está presente nas motivações ideológicas do autor, na escolha das histórias e dos personagens. E o merchandising de ideias está ligado ao merchandising comercial, pois ao retratar um determinado ambiente social, seus hábitos, serão necessários relacionar quais melhores produtos a serem veiculado no merchandising comercial. Uma questão importante a observar é para qual público se destina esses vários tipos de merchandising, pois que a sociedade brasileira é extremamente desigual, notadamente no aspecto econômico e, também, pelo fato de grande parcela da população não ter acesso aos bens culturais, bem como à saúde e educação de boa qualidade. Uma parcela restrita da população tem acesso aos produtos oferecidos pelo merchandising nas telenovelas, enquanto a outra parcela, que é majoritária, só consome esses produtos e compartilha o merchandising de ideias a nível imaginário (KHEL, 1986). 
O merchandising de ideias e valores que predomina nas telenovelas da Rede Globo é principalmente dos grandes centros urbanos (do eixo Rio - São Paulo), ressaltando um país moderno, desenvolvido, sem contradições, explorações e diferenças (RAMOS, 1986). Produtos, hábitos e comportamentos estão relacionados com uma publicidade que procura vender, portanto, não apenas produtos, mas concepções de mundo e um novo modelo para o país que almeja abandonar o passado arcaico e aderir ao moderno. Várias telenovelas também estimularam modismos, ao associar o merchandising comercial e o de ideias, pois o produto também era associado a algum significado que a ação de merchandising procurava veicular (RAMOS, 1986, p. 90). Esse significado possui vários símbolos que transitam entre a exposição do produto, a ação do personagem e suas inserções na trama, pois um personagem usa certo tipo de roupa, dirige um modelo de carro, vai ao banco e participa de um evento social, como se tudo isso fosse também comportamentos "naturalizados", reconhecidos socialmente por toda sociedade.

Produtos diversos são oferecidos numa mesma telenovela, como serviços bancários (uma publicidade do Itaú), um refrigerante (guaraná Antártica), ou mesmo uma pomada analgésica (Gelol). A novela Partido Alto, de Gilberto Braga e Aguinaldo Silva, exibida em 1984, é um exemplo de como o merchandising comercial e de ideias foi bem explorado. Nela as atrizes utilizavam um adereço (no caso um brinco) que tornou-se popular entre as mulheres, bem como popularizou uma dança, o $b r e a k^{3}$, muito popular nos E.U.A, no início dos anos 80, entre os negros, e a novela procurou popularizá-la aqui no Brasil no seu ano de exibição. (RAMOS, 1986, p.106-107).

Os dados coletados pelo anuário elaborado pelo Observatório IberoAmericano de Ficção Televisiva, em 2008 ressaltam que a publicidade e, portanto, o merchandising comercial e social possui uma presença importante na produção ficcional. Essa pesquisa desenvolvida por vários estudiosos ${ }^{4}$ evidenciou que a ficção brasileira atraiu inúmeros anúncios publicitários e, com isso, a narrativa ficcional se tornou cada vez mais alterada para comportar a presença do merchandising. A telenovela oferece um espaço privilegiado, portanto, para a publicidade, sendo o

\footnotetext{
${ }^{3} \mathrm{O}$ break é uma dança que surgiu entre os garotos pobres dos bairros do Harlem e Bronx em Nova York. Chama-se break porque assemelha uma "quebra" na performance e também de artes marciais. O cantor Michael Jackson é considerado um dos maiores performáticos dessa dança.

${ }^{4}$ Os países envolvidos na pesquisa e na elaboração do Anuário (Obitel) 2009 - com os dados referentes a 2008 - foram México, Chile, Argentina, Brasil, Espanha, Portugal, E.U.Ae Uruguai. Cada país teve uma equipe responsável tendo como organizadores Maria Immacolata Vassallo de Lopes e Guilherem Orozco Gómez.
} 
merchandising comercial sua principal forma de inserção, pelo menos é isso que está evidenciado nas produções dramatúrgicas dos países pesquisados de 2008, segundo o anuário. $\mathrm{O}$ alcance que esse gênero dramatúrgico ainda possui na sociedade ainda atrai um número considerável de anunciantes, por isso a prática do merchandising comercial.

O merchandising social veicula mensagens socioeducativas nas tramas das telenovelas, ele o faz não para vender produtos, mas estimular a reflexão acerca de determinados comportamentos e com características que aproximam de uma campanha publicitária, por isso que possivelmente a Rede Globo irá nomeou a prática de merchandising social, bem próxima de um marketing social. O merchandising torna-se um elemento imprescindível para a Rede Globo produzir suas ficções e, no caso do merchandising social atuando de forma explícita na narrativa, ele pode ser considerado um instrumento às mãos da emissora para a promoção de ações educativas.

Lopes (2001), possivelmente utilizando a perspectiva de Bourdieu de troca simbólica, analisava a relação entre a educação e a teledramaturgia. Entendendo a educação não restrita apenas às instituições formais, mas como sendo praticada informalmente na família, entre amigos ou mesmo em espaços como a televisão. A teledramaturgia, ao incorporar a prática do merchandising social, procura realizar também uma prática educativa. Essa concepção vem sendo discutida também por outros estudiosos como Schiavo (1995) que ressalta o elemento educativo do merchandising social, ao dizer que:

\footnotetext{
Merchandising social é a inserção intencional e motivada por estímulos externos de questões sociais nas tramas das telenovelas. Esta inserção tanto pode ocorrer nas tramas principais como nas paralelas. Através do merchandising social, criam-se oportunidades para interagir com as telenovelas, compondo momentos da vida dos personagens e fazendo com que atuem como agentes formadores de opinião e/ou introdutores de inovações sociais. Enquanto estratégia de mudança de atitudes e mudança para novos hábitos, o merchandising é um instrumentos dos mais eficientes, tanto pelo elevado número de pessoas que atinge quanto pela forma como demonstra a efetividade do que se está promovendo (SCHIAVO, 1995, p. 107).
}

Schiavo (1995) analisa como a educação está presente na prática do merchandising social a partir da proposta do entertainment-education isto é, utilizar o entretenimento para educar. Esse processo é analisado e difundido a partir dos anos 70, 
por estudiosos como Singhal, Rogers e Brow ${ }^{5}$. A prática do entertaiment-education foi utilizada por vários países na América. Um exemplo ainda na década de 70, foi quando estúdios Walt Disney produziram vários desenhos animados, história em quadrinhos e cartazes e os classificaram como sendo educativos, transmitindo uma mensagem principalmente de planejamento familiar. Outro exemplo foi a utilização dos superheróis (ex: Superman) como divulgadores do planejamento familiar, pela empresa Warner Communications. Todas essas iniciativas estavam sendo realizadas para a IPPF (International Planned Parenthood Federation). Porém, esses programas produzidos pela Disney e pela Warner, como os desenhos animados, tendo o Pato Donald, como principal exemplo e os super-heróis também revelam algumas questões pertinentes como um discurso que não problematiza as relações de classe, revelando personagens como se fossem assexuados e reforçando uma ideologia dominante, especialmente a do E.U.A.

Outro desdobramento do entertaiment-education se deu na produção musical, com o intuito de divulgar mensagens sobre AIDS, dependência química e sexo responsável, dirigido principalmente aos adolescentes. Essas campanhas foram coordenadas pela Population Communication Service ${ }^{6}$ e foram produzidas músicas em diversos países como México, Filipinas, Burkina Fasso e Nigéria, com letras que continham mensagens sobre o sexo seguro e planejamento familiar, (SCHIAVO, 1995, p. 50). Entretanto, em relação à telenovela, o processo de entertaiment-education era experimentado no México no final da década de 60 sob as orientações de Miguel Sabido, executivo da Televisa, a maior emissora de televisão daquele país e também a maior produtora de telenovelas. Sabido defendia que era possível inserir questões sociais, e com isso educar a população através de programas televisivos como a telenovela:

Se era possível vender máquinas de costura por meio de mensagens veiculadas nas telenovelas - pensou Sabido - porque não poderia vender, também, programas para alfabetização para adultos ou estimular o uso adequado de equipamentos e serviços sociais

\footnotetext{
${ }^{5}$ Esses autores segundo Schiavo, através do ensaio Entertaiment-education soap opera for development: lesson learned, difundiram o termo e o definiram como o processo pelo qual inserem conteúdos educacionais em mensagem de entretenimento, com o objetivo de aumentar o conhecimento sobre determinada questão para promover atitudes favoráveis e mudanças de comportamento.

${ }^{6}$ Population Communication Service é um projeto financiado pelo governo norte-americano através do USAID (Agência dos E.U.A para desenvolvimento internacional) em colaboração com a Academia de desenvolvimento educacional e a universidade Johns Hopkins produzindo estratégias para a educação de jovens, saúde infantil e acesso a novas tecnologias. Disponível em: http://pcs.aed.org/. Acessado em $14 / 10 / 2010$.
} 
oferecidos pelo governo? Será possível influenciar o comportamento dos telespectadores enquanto consumidores-pontenciais, porque não poderia fazer o mesmo, enquanto cidadãos, visando o exercício dos seus direitos? (SCHIAVO, 1995, 67)

Na novela de 1969, Simplesmente Maria, Sabido inseriu a experiência de mensagens educativas, como essas citadas acima, e outras como vender máquinas de costura para educar as pessoas ao trabalho. Em outras telenovelas ficam nítidas as mensagens educativas. Em Ven Conmigo, de 1975, a temática central é sobre alfabetização e as vantagens da educação. Uma outra telenovela de Sabido, Acompáñame (1977), insere a temática do planejamento familiar, questão bastante polêmica num país como o México, que é de maioria católica e cuja igreja condenava os métodos artificiais de contracepção. A partir dessas experiências, Miguel Sabido produziu mais telenovelas, inserindo mensagens educativas, perfazendo um total de seis novelas, que são Vamos juntos (1979), sobre as temáticas da criança, dos laços familiares e paternidade responsável. El combate (1980), que volta ao tema sobre a alfabetização de adultos, agora direcionada às áreas rurais. Caminemos (1980/1981), sobre educação sexual para jovens e, a última, Nosotros las mujeres (1981), sobre o tema da desigualdade entre o homem e mulher numa sociedade machista.

Essas considerações ressaltam que o merchandising social possui uma função explicitamente pedagógica, ou melhor, que assume essa função a partir das relações de produção estabelecidas. Nicolosi (2009) procura articular a preocupação em destacar o merchandising social como uma ação pedagógica explícita inserida nas tramas da novela e que, principalmente nos últimos anos, ficou cada vez mais constante. Recorrendo a P. Bourdieu observa-se o caráter dinâmico, processual e complexo da atividade pedagógica, mas também arbitrária, existindo, portanto, dois tipos de ação pedagógica a formal e a informal. A última muitas vezes é engendrada através de um processo explícito, por relações de poder, inculcando, valores e símbolos dos grupos dominantes.

No entanto, compreender como o termo merchandising social é utilizado para definir as ações pedagógicas nas telenovelas atuais, requer atenção para perceber a complexidade da utilização do termo e não cair em "armadilhas" conceituais, como afirma P. Bourdieu, na doxa do campo. Por que em certas circunstâncias históricas "privilegiou-se" se apropriar do termo merchandising social para caracterizar essas ações com significados didáticos-pedagógicos? 
É necessário afastar-se do subjetivismo como está evidenciado na afirmação de Glória Perez "eu inventei o merchandising social”, e até de uma explicação economicista de um materialismo ortodoxo de que essa apropriação seria para atingir objetivos meramente comerciais, fruto da estandardização dos produtos culturais. $\mathrm{O}$ mérito de muitos trabalhos anteriores sobre a temática foi compreender o processo de merchandising social nas telenovelas, porém há uma escassez em problematizar por que se utiliza esse termo e, também, nesses próprios trabalhos as discussões não avançam em desvincular a compreensão apenas ao âmbito da área da publicidade. Quais as implicações da prática do merchandising social e porque o termo aglutinou toda ação de caráter pedagógico inserida na narrativa da telenovela.

O processo de mudança na narrativa e possivelmente na estética, analisada por estudiosos como Esther Hamburger, ressalta que no início da década de 90 as telenovelas, principalmente as da Rede Globo, passaram por uma mudança na sua estrutura, especialmente na relação com a audiência. A isso Hamburger considera novelas de intervenção. Citando exemplos como de Corpo e Alma (1992), Explode Coração (1995) e O Clone (2001), todas da autora Glória Perez, e Por Amor (1997), Laços de Família (2000) e Mulheres Apaixonadas (2003), estas do autor Manoel Carlos, todas produzidas pela Rede Globo, Hamburger considera que esses autores "carregam no tom didático e na pretensão pedagógica das novelas" (HAMBURGER, 2005, p.135).

Segundo dados do Obitel só no ano de 2008 todas as telenovelas da Rede Globo inseriram práticas de merchandising social em suas tramas. Essa observação evidencia a trajetória que as telenovelas da Rede Globo estavam tendo a partir desse período e, com isso, as preocupações da emissora. Percebe-se que, a partir dos dados fornecidos pela própria emissora, e destacados no Obitel de 2008, os principais temas abordados nas telenovelas do período retratado estão relacionados à saúde qualidade de vida e valores, princípios e relações humanas. Temas que destacam o bem estar dos indivíduos, uma exigência cada vez maior da vida moderna, e também elementos morais que acentuam características positivas para influenciar o comportamento desses mesmos indivíduos.

Porém, Hamburger (2005) considera que existem novelas que conseguem aprofundar a discussão, ou melhor, operar a intervenção de forma mais sofisticada, como ocorreu em O Rei do Gado, (novela de Benedito Ruy Barbosa) que mobilizou vários debates sobre o movimento social dos Sem-Terra. Essa novela conseguiu no período de sua veiculação produzir uma pauta - como aponta a perspectiva da agenda 
setting $^{7}$ - procurando construir um debate acerca das invasões de terra, do campo político, quando se referia ao senador (personagem presente na novela) e ao produtor rural (também personagem na novela). Se na hipótese da agenda-setting existe um prazo para que as pautas, isto é, os temas, sejam colocados pela mídia e recepcionados pelo público, na telenovela esse prazo é acelerado, devido ao ritmo de sua produção e as características de serialização que possui.

Hamburger (2005) identificou a presença constante das novelas de intervenção a partir dos anos 90, utilizando a prática do merchandising social, exemplificada a partir do Rei do Gado, considera que as novelas de intervenção seriam um "aprofundamento" da prática, do merchandising social. Observa também à dimensão pedagógica da intervenção da telenovela junto à audiência, bem como outro elemento, a construção de um espaço público momentâneo para inserções de temáticas sociais.

As novelas de intervenção, como destacado no capítulo anterior, são produzidas pela Rede Globo a partir da década de 90 com o objetivo de servir de espaço para utilidade pública, aproximando-se da realidade e inserindo na ficção temas do cotidiano para produzir um debate, ou mesmo modificar comportamentos. Essa prática passa a ser nomeada de merchandising social, pois a proximidade com a área da publicidade contribuiu para ressignificação do termo e sua prática, bem como sua popularização. O termo merchandising social possui, na verdade, várias interfaces com o marketing e seu desdobramento no marketing social e com a educação, mais especificamente com o processo de entertaiment-education. É considerada de intervenção, ou novela pedagógica, pois possui mensagens didáticas para a mudança de atitudes sobre diversos tipos de temas (AIDS, educação sexual, violência doméstica, saúde pública) nas telenovelas da Rede Globo no final do século XX é sintetizado no termo merchandising social, tornando-se, portanto, a prática desse elemento intervencionista, ou pedagogizante.

\footnotetext{
${ }^{7}$ Agenda-setting é considerada por muitos estudioso como Mauro Wolf uma hipótese em que a mídia consegue, a médio e a longo prazo, inculcar determinados conceitos e temas que são incluídos na agenda dos indivíduos.
} 


\subsection{Merchandising social e as implicações do termo na televisão}

Compreender não somente a utilização do termo, mas perceber como através do merchandising social, a televisão procura se aproximar da recepção, percebendo a importância do mesmo nas telenovelas e para isso é necessário desconstruir a apropriação e a utilização do termo. Por tratar de mediação e remeter a processos sociais, recorrer-se-à a autores que auxiliarão nessa compreensão, alguns desses são Raymond Williams e J. Mantin-Barbero.

Para Williams (1980), é necessário analisar os processos sociais e a produção cultural a partir da articulação dos conceitos "caros" ao marxismo, quais sejam os de base e superestrutura. Williams atentava para entender como a cultura e os processos sociais devem ser percebidos a partir de uma relação de produção material, mas de significados e valores em situações específicas e históricas. Como a cultura e, com isso, as próprias relações sociais são construídas historicamente, Williams observa que é necessário perceber como as produções culturais, mesmo não tendo aquele condicionante do determinismo econômico, possuem elementos relacionados com as condições materiais e históricas de cada sociedade.

Utilizando essa perspectiva de Williams e buscando compreender como o termo de merchandising social torna-se "utilizável” e "popularizado", recorre-se ao conceito de tradição seletiva, que o pensador usa para analisar como a sociedade seleciona elementos do passado para mantê-los no presente, como hegemônicos. A "naturalização" rápida desse termo dentro da televisão e da telenovela pode ser percebida como o processo da tradição seletiva, sendo incorporado dentro dos grupos hegemônicos da sociedade na atualidade.

A partir da perspectiva de Williams (1980), pode-se analisar o processo de apropriação e utilização do termo, e o porquê de a Rede Globo o utilizar para nomear as várias práticas inseridas nas suas telenovelas, seja de marketing social, seja entertaiment-education, ou mesmo de intervenção. A questão colocada anteriormente é novamente refeita: Por que o termo merchandising é apropriado e utilizado pela Rede Globo? A seletividade operada pela cultura pode subsidiar a compreensão, pois no processo de construção da telenovela o termo foi apropriado a partir de outras áreas, como o marketing e mais especificamente, a publicidade. Essa seletividade ressaltada na obra de Williams suscita a problematização da utilização e popularização desse termo. 
Normalmente $\mathrm{n}$ es muy difícil demostrar es situacion desde uma perspectiva empírica. La mayoría de las versiones de la <<tradición〉> pueden ser rápidamente demostradas em su modalidad racicalmente selectiva. A partir de um área total posible del pasado y el presente, dentro de uma cultura particular certos signficados y práticas son seleccionados y acentudados y otros significados y práticas son rechazados o excluídos. Sin embargo, dentro de uma hegemonia particular, y como uno de sus procesos decisivos, esta selección es presentada y habitualmente admitida con éxito como $<<$ la tradción $>>$, como el <<pasado signigicativo >> [...] (WILLIAMS, 1980, p. 138).

O que importa destacar na perspectiva aberta de Williams é sua contribuição e como ele observa a permanência de certas práticas significativas "herdadas" na sociedade, mas que possivelmente possam ser reelaboradas continuadamente pelo processo histórico. Se entendermos a televisão como um espaço hegemônico dentro da sociedade e que o próprio pensador ressalta que possui "limites e pressões específicos e compensações", pode-se compreender que o termo, na verdade, ultrapassa meramente uma simples apropriação de outra área e percebe-se como situado em P. Bourdieu uma dimensão de negociação simbólica.

O termo merchandising social, portanto, não seria apenas uma transposição de uma área (no caso da comunicação = publicidade e da administração) para ser utilizado com outro significado por outras áreas, como no caso a área da dramaturgia. Porém, o processo da apropriação, da utilização e da possível "popularização" do termo é complexo em sua compreensão, bem como na sua própria prática. Essa complexidade, como está sendo abordada remete para uma troca simbólica entre campos (Bourdieu), ou mesmo a seletividade operada pela cultura (Williams).

Mesmo que o termo não possua uma "tradição institucionalizada" na sociedade, pois é utilizada em áreas específicas e agora adotada dentro de um gênero também específico, a telenovela, fazendo parte de uma narrativa ficcional, ele procura dialogar coma realidade, com a maior verossimilhança possível. Dessa forma, a questão mais pertinente não é por que justamente esse termo está sendo utilizado, mas como ele é utilizado e como tornou-se um "lugar comum," a partir do qual associam merchandising social à vários processo que envolvem um possível comprometimento de organizações com ações sociais, visando algum tipo de mudança coletiva, como marketing social, responsabilidade social e entertaiment-education. Estudos como o de Schiavo (1995) demonstraram que o merchandising social, no caso sua prática, provém da área de marketing e, mais especificamente, do marketing social e é reelaborado na 
narrativa ficcional com um significado pedagógico. Assim, a utilização do termo se insere numa apropriação estratégica e simbólica, principalmente no espaço comunicacional.

Essa incorporação do termo merchandising social pela teledramaturgia, pode se compreendida também a partir da análise de Bourdieu (2004). Para o sociólogo a sociedade é constituída por campos e entre eles existe um processo de trocas ideológicas e simbólicas. Bourdieu analisa como o campo religioso incorporou vários elementos do campo econômico, a partir da perspectiva aberta por Max Weber (Bourdieu, 2004). Identificou também trocas simbólicas entre o campo educacional com outros campos, principalmente o econômico. Essas trocas são realizadas, pois um campo constituído de estruturas objetivas, representações coletivas, também possui elementos simbólicos que são construídos, mas também incorporados de outros campos.

Bourdieu (2004) ao perceber a troca entre esses campos nos oferece a compreensão de como o campo da mídia, em específico da televisão incorpora constantemente elementos objetivos e simbólicos de outros campos. Em outras obras como Sobre a Televisão (1997) e Contrafogos I (1998) o pensador não só observa as trocas entre os campos da mídia e o econômico, como adverte para relações de dominação, quando elementos de outros campos, passam a se tornar arbitrários e produzir violência simbólica.

Desejaria, então, desmontar uma série de mecanismos que fazem com que a televisão exerça uma forma particularmente perniciosa de violência simbólica. A violência simbólica é uma violência que exerce com a cumplicidade tácita dos que a sofrem e também, co freqüência, dos que a exercem, na medida em que uns e outros são inconscientes, de exercê-la ou de sofrê-la. A sociologia, como todas as ciências, tem por função desvelar coisas ocultas; ao fazê-lo ela pode contribuir para minimizar a violência simbólica que se exerce nas relações sociais e, em particular, nas relações de comunicação pela mídia (BOURDIEU, 1997, p. 22).

Se o campo da mídia incorpora elementos de outros campos, um dos principais é o campo econômico, pois que este tem no capitalismo, seu principal sistema norteador. Competição, concorrência, busca pela audiência ao máximo possível, obtenção de lucro de forma imediata são exemplos de como elementos do campo econômico tornam-se arbitrários na televisão. Essa perspectiva nos orienta para compreender como o termo merchandising, ou mesmo sua prática estão presentes no campo econômico, contribuindo para que o capitalismo possa oferecer produtos e 
serviços para o consumo. Nesse sentido, como ressalta Bourdieu, o campo da mídia, no caso a televisão, está cada vez mais incorporando elementos do campo econômico e com isso podemos perceber como o merchandising comercial na teledramaturgia e o social estão presentes.

\section{CONSIDERAÇÕES}

A preocupação dos trabalhos anteriores sobre merchandising social, quando trata da incorporação do termo - pelo menos grande parte deles - é descrever como o termo é apropriado e como se populariza a partir de outra área no caso do marketing. No entanto, escapa a problematização sobre como o termo perpassa e ultrapassa meramente uma "publicidade social”. Como a televisão é uma formação cultural, observação realizada por Martin-Barbero, a partir de R. Williams, as suas características também possuem valores e significados que estão em processos de ressignificação constante. $\mathrm{O}$ do marketing, participa de um processo de significação contínua. O merchandising social pode ser compreendido num processo de ressignificação a partir de outros conceitos e práticas existentes, como foram abordados e no espaço da televisão, já que essa permite uma capacidade de ressignificar práticas usuais e reelaborá-las.

A familiaridade produzida pela televisão talvez seja uma das grandes responsáveis pela própria popularização do termo merchandising social e não apenas de sua incorporação e recepção, que nesse último caso ainda necessita de outros estudos, que serão realizados em outros momentos deste trabalho. A capacidade que a TV possui de aproximar a ficção e o cotidiano, e o próprio espaço que ela possui de fluxo contínuo, ritmo intenso, permite essas incorporações e diálogos com vários espaços. Nesse caso, o termo merchandising social, pelo menos utilizado na telenovela torna-se "rapidamente" incorporado ao vocabulário de autores, atores, diretores, ou melhor, num campo (ou um subcampo?) de dramaturgia televisiva.

O termo merchandising social possui uma dinâmica que está acompanhando as próprias mudanças da telenovela. Para compreendê-lo é necessário situar os processos sociais que estão presentes no processo de incorporação do mesmo na dimensão da ficção televisiva. O dinamismo que a própria televisão possui e seu ritmo de serialização contribui para que a própria "performance" do merchandising social e a utilização do termo também possuam modificações influenciada pela própria dinâmica da televisão e da teledramaturgia. 


\section{REFERÊNCIAS}

BAKER, Michael J. Marketing theory: a student text. New York: Thomson, 2000.

BLESSA, Regina. Merchandising no ponto-de-venda. 4 ed. São Paulo: Atlas, 2006.

BOURDIEU, Pierre. A Economia das trocas simbólicas. 5 ed. Lisboa: Ed. Perspectiva, 2003. Col. Estudos - 20.

Contrafogos: táticas para enfrentar a invasão neoliberal. Rio

de Janeiro: Jorge Zahar Ed., 1998.

. Sobre a Televisão. Rio de Janeiro: Jorge Zahar Ed, 1997.

COSTA, Alcir Henrique da; Khel Maria Rita; Simões, Inimá Ferreira. Um país no ar: história da TV brasileira em 3 canais. São Paulo: Brasiliense, 1986.

KOTLER, Philip. Administração de marketing: análise, planejamento, implementação e controle. 5 ed. São Paulo: Atlas, 1998.

LEVEK, Andréa Regina H. Cunha \& outros. A responsabilidade social e sua interface com o marketing social. Revista FAE: Curitiba, v 5, n 2 p. 15-25, maio-agosto de 2002.

NICOLOSÍ, Alejandra Pía. Merchandising social na telenovela brasileira. Um diálogo possível entre ficção entre ficção e realidade em Páginas da Vida. Dissertação (Mestrado. em Ciências da Comunicação). Escola de Comunicação e Artes. Universidade de São Paulo. São Paulo. 2009.

ORTIZ, Renato. Telenovela: história e produção. Renato Ortiz; Silva Helena Simões Borelli; José Maria Ortiz Ramos. 2ª ed. São Paulo: Brasiliense,1991.

OBITEL: Observatório Ibero-americano de ficção televisiva. Coord: Maria Immacolata Vassallo de Lopes e Guilherme Orozco Gómez. Rio de Janeiro: Editora Globo, 2009.

PALLOTTINI, Renata. Dramaturgia de Televisão. São Paulo: Moderna, 1998.

PRINGLE, Hamish: THOMPSON, Marjorie. Marketing social: marketing para causas sociais e construção das marcas. São Paulo: Makron Books, 2000.

RAMOS, Roberto. Cultura e merchandising nas novelas. 3 ed. Petrópolis: Vozes, 1986.

SCHIAVO, Marcio Ruiz. Merchandising social: uma estratégia sócio-educacional para grandes audiências. Rio de Janeiro. Tese de livre-docência. Universidade Gama Filho, 1995.

WILLIAMS, Raymond. Marxismo y literatura. Barcelona: Ediciones Península, 1980. 
Original recebido em: 15/11/2011

Aceito para publicação em: Novembro de 2013

Plábio Marcos Martins Desidério

Doutor em Comunicação pela Universidade de Brasília e Mestre em Sociologia pela

Universidade Federal de Goiás. Professor Adjunto I da Universidade Federal do

Tocantins. 